\title{
REUTILIZAÇÃO DE ÁGUA DA CHUVA
}

\section{ARTIGO ORIGINAL}

JUNIOR, Jailton Muniz Mendes ${ }^{1}$

ROCHA, José Herique Dos Santos ${ }^{2}$

CHAVES, Thiago Uchoa ${ }^{3}$

NASCIMENTO, Rudgero Oliveira Do ${ }^{4}$

JUNIOR, Jailton Muniz Mendes. Et al. Reutilização de água da chuva. Revista Científica Multidisciplinar Núcleo do Conhecimento. Ano 05, Ed. 06, Vol. 05, pp. 6690. Junho de 2020. ISSN: 2448-0959, Link de acesso: https://www.nucleodoconhecimento.com.br/engenharia-civil/reutilizacao-deagua

\section{RESUMO}

A água é essencial à sobrevivência humana e ao desenvolvimento das sociedades. Com o aumento da população, o uso inconsciente da água e a degradação ao meio ambiente, limitou-se a disponibilidade desse recurso no planeta. Esta revisão busca demonstrar as formas que a Engenharia tem de preservar este recurso natural advindo da chuva, salientando que os sistemas de aproveitamento de água da chuva são alternativas sustentáveis e desde a antiguidade já se faziam o uso dessa técnica. O presente trabalho avalia, conforme literatura sobre o tema, o aproveitamento da água da chuva de acordo com o sistema de captação desta na construção civil. A

\footnotetext{
${ }^{1}$ Graduando em Engenharia Civil.

2 Graduando em Engenharia Civil.

${ }^{3}$ Graduando em Engenharia Civil.

${ }^{4}$ Especialização em MBA em Gerenciamento de Obras de Engenharia. Graduação em Engenharia Civil.
} 
metodologia que pautou essa discussão foi qualitativa e exploratória, tendo por base estudos feitos e documentos que tratam da temática abordada incluindo artigos primários e de revisão pautado em procedimentos técnicos e bibliográficos datados de 2000 à 2019. E ainda com normas da ABNT datadas de 1992 até 1998. Assim, percebe-se que o reaproveitamento de água da chuva é uma alternativa sustentável que só traz benefícios ao profissional de engenharia e a sociedade em geral, a com custo benefício que vai se tornando cada vez mais positivo do ponto de vista sustentável para as gerações futuras e sendo crucial de ser implementado no contexto da construção civil.

Palavras-chaves: Água de chuva, aproveitamento, captação, construção civil.

\section{INTRODUÇÃO}

A crise ambiental e a escassez de água que o mundo atual enfrenta, põe em risco o desenvolvimento das sociedades e a sobrevivência humana. A sustentabilidade é uma provável medida para resolução dessa problemática. No entanto, a poluição das bacias hidrográficas, o uso inconsciente da água e o aumento da população limitaram ainda mais a disponibilidade desse recurso na natureza (MAY, 2004).

É fato que a construção civil é uma das atividades humanas que mais causam danos ao meio ambiente. Segundo dados da ANAB (Associação Nacional de Arquitetura Bioecológica), cerca de $50 \%$ dos recursos extraídos da natureza são destinados ao setor (ANTUNES, 2004).

Dessa maneira é importante tratar sobre o reaproveitamento da água e baseando-se nessa questão é válido destacar que a partir da perspectiva de atingir metas consideradas positivas, sendo necessária uma mudança no consumo da água atual, vez que a escassez da água é latente e assim faz-se necessário investimentos em desenvolvimento tecnológico e na busca de soluções alternativas para a ampliação da oferta de água, como, por exemplo, a utilização da água de reuso. 
Neste contexto é fato que devem ser buscadas soluções adequadas para manutenção desse recurso, e a Engenharia deve procurar medidas e soluções que evitem tanto desgaste à natureza, por isso que a ideia de sustentabilidade é tão difundida como meio de melhorar todo o tradicional processo de construção, fazendo com que o consumo de bens naturais seja mais regrado e sejam substituídos os recursos renováveis, e nos não renováveis tentar usar o mínimo ou substituir estes por materiais reciclados, através do uso de tecnologias existentes que visam um que primam pela sustentabilidade e pelos procedimentos ecologicamente corretos (ARAGÃO et al., 2013).

A necessidade de se construir um novo método de desenvolvimento tornou-se evidente pelo fato da percepção de que não se pode crescer economicamente e populacionalmente em grande escala, em um planeta onde os recursos naturais são limitados. A definição de desenvolvimento sustentável é desenvolver para atender as necessidades do presente, sem comprometer a gerações futuras, de atender as suas próprias necessidades. Dentro de uma residência a água potável é utilizada para diversos fins e uma parcela significativa é destinada para uso menos nobre. $\mathrm{O}$ consumo de água potável, para fins não potáveis pode chegar a $84 \%$ em uma residência, desse valor a bacia sanitária é responsável por 38\% (PNCDA, 2002).

Estimativas de estudos feitos com esse tema mostraram que uma residência com 4 pessoas, utilizando-se da descarga sanitária 5 vezes ao dia atingiu um consumo mensal de 3.600 litros de água. Toda essa água é proveniente da estação de tratamento e segue todos os parâmetros de potabilidade (ARAGÃO et al., 2013).

Assim, vê-se grande viabilidade de aproveitar água da chuva para uso não potável, e com todos os problemas relacionados à limitação do uso da água doce, concomitante ao crescimento populacional, aliados à má utilização da água potável utilizada para as necessidades humanas, vem à importância da captação da água da chuva para fins potáveis e não potáveis. Há milhares de anos atrás já se usavam dessa técnica para armazenar água e usa-las nos períodos de estiagem (TIBAYUKA, 2008). 
Diante destas questões este trabalho tem como objetivo geral tratar sobre o aproveitamento da água de chuva para uso não potável e para tanto, a proposta é de fazer uma revisão bibliográfica sobre o tema, trazendo os principais aspectos técnicos e econômicos a respeito do reuso e captação de água da chuva.

Sendo assim, são necessárias ações para a eficiente gestão da demanda do uso da água, reduzindo os índices de perdas e desperdícios, muitas vezes inconscientes e para que a água continue sendo uma fonte acessível, faz-se necessário adotar medidas sobre a renovação deste recurso, bem como, uma mudança de hábitos da sociedade, de modo a orientar as ações públicas e privadas no intuito de otimizar a utilização dos recursos hídricos.

\section{REUTILIZAÇÃO DA ÁGUA DA CHUVA NA CONSTRUÇÃO CIVIL}

\subsection{RECURSOS HÍDRICOS: ASPECTO GLOBAL}

A hidrosfera tem um volume estimado em 1,46 bilhões de quilômetros cúbicos de água, porém toda essa abundância não é adequada para o consumo ou não está disponível para uso imediato. Países com dimensões continentais ou situados nos trópicos são os mais agraciados pela natureza em recursos hídricos destacando-se Brasil, Canadá, China, Indonésia, Estados Unidos da América, Índia, Bangladesh, Myanmar, Colômbia e Zaire (JUNIOR, 2004).

De acordo com o Relatório 4 do World Water Assessment Programme - WWAP (UNESCO, 2012), as políticas e os programas de gestão da água precisam considerar a constante variação de disponibilidade dos estoques de água.

\subsection{RECURSOS HÍDRICOS: ASPECTO NACIONAL}

A vazão média anual dos rios em território brasileiro é de 179 mil m³/s (5.660 km³/ano) segundo os dados apresentados pela ANA - Agência Nacional de Águas, levando em consideração a vazão média de descarga (ANA, 2005). O Brasil pode ser considerado 
uma região privilegiada por possuir $12 \%$ da capacidade hídrica da superfície do planeta Terra (THOMAZ, 2005).

Mesmo o Brasil tendo toda essa disponibilidade hídrica, apresenta uma grande variação espacial e temporal de vazões. As bacias que ficam situadas em áreas que apresentam baixa disponibilidade e grande demanda de recursos hídricos têm características claras de escassez e estresse hídrico (ANNECCHINI, 2005).

A população brasileira gira em torno de 202.768 .562 pessoas IBGE- Instituto Brasileiro de Geografia e Estatística (IBGE, 2014), o crescimento acentuado da população contribui gravemente para escassez de água, outro fator relevante é a distribuição da população pelo território brasileiro, podendo causar uma forte demanda em regiões com grande urbanização (ALMEIDA et al., 2010).

\subsection{CICLO HIDROLÓGICO}

Através do processo de radiação solar e do metabolismo dos seres vivos, praticamente toda a água existente no planeta, nos seus diferentes estados físicos estão em permanente circulação, desenvolvendo um processo denominado ciclo hidrológico (SANTOS et al., 2001).

O ciclo hidrológico é responsável pela reposição das bacias. Em síntese, o ciclo hidrológico envolve cinco processos: a evapotranspiração; a evaporação; a precipitação; o escoamento superficial e 0 escoamento subterrâneo (VASCONCELOS; FERREIRA, 2007) conforme apresentado abaixo (Figura 1). 
Figura 1: Ciclo Hidrológico

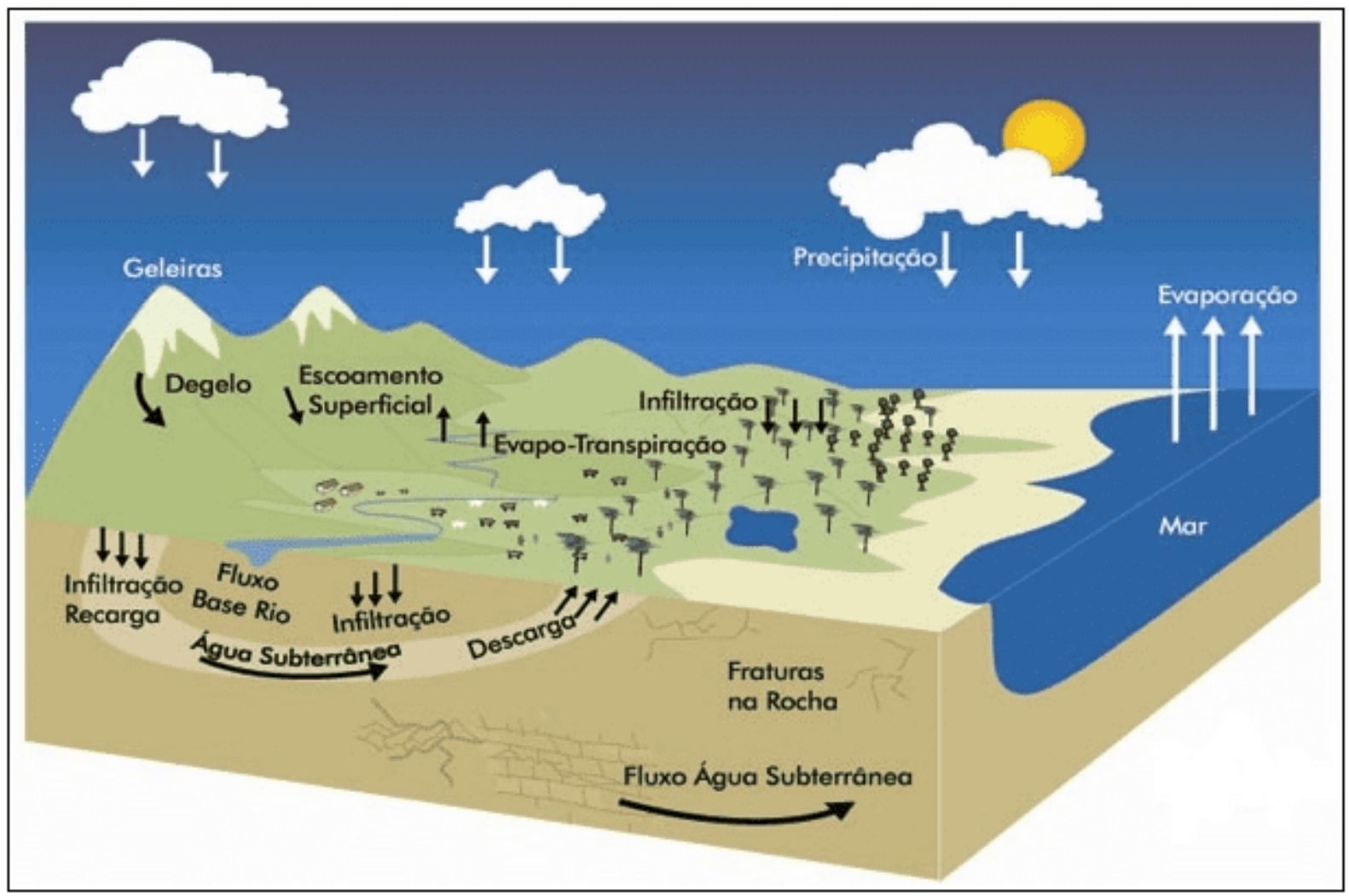

Fonte: Ministério do Meio Ambiente, MMA, (2015).

\subsection{DEMANDA DE RECURSOS HÍDRICOS}

De acordo com ALMEIDA et al (2010), a água potável é utilizada em diversas atividades nas edificações. Dentre estes diversos usos da água, uma parcela significativa está destinada a fins não potáveis, como descarga de vasos sanitários, rega de jardins, limpeza de automóveis e calçadas.

Destarte, a captação de água da chuva serve de instrumento que ajuda nesta problemática, e os fatores que incidem como motivos para que seja implementado projetos que visem a redução de custos e que busquem a sustentabilidade são essenciais na sociedade hodierna (MORAES, 2002). 
Segundo dados do Programa Nacional de Combate ao Desperdício de Água - PNCDA (2002), foi estimada a média de utilização de água em residências por ponto de consumo como mostra os gráficos na (Figura 2).

Figura 2: Utilização de água em residências por ponto de consumo

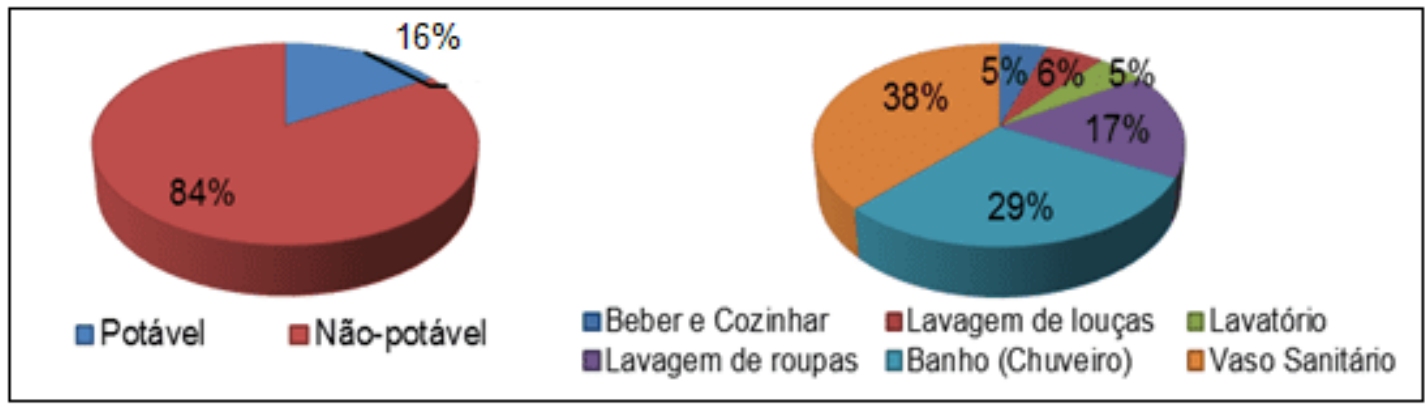

Fonte: HESPANHOL (2003).

O gráfico permite a análise do consumo de água potável em uma residência para os diversos fins, $84 \%$ da água potável consumida é usada para fins não potáveis e apenas $16 \%$ é usada para fins potáveis.

Do consumo de água por atividades dentro de uma residência os três maiores vilões do consumo são em primeiro lugar e destacado nesse estudo, os vasos sanitários com $38 \%$, logo em seguida o consumo dos chuveiros de $29 \%$ e depois a lavagem de roupa com $17 \%$ do consumo.

\subsection{APROVEITAMENTO DA ÁGUA DE CHUVA}

O aproveitamento da água pluvial não está entre as ações mais essenciais no desenvolvimento sustentável. A água que cobre cerca de $70 \%$ da superfície da Terra é uma substância essencial para a natureza e o ecossistema do mundo. Possui várias propriedades químicas e físicas únicas que a tornam indispensável à vida e, de fato, compõe cerca de $60 \%$ do peso corporal do ser humano. É relatado que a água é agrupada em águas atmosféricas, superficiais e subterrâneas, onde a água atmosférica inclui a umidade contida na nuvem, que precipita como neve e chuva (YEASMIN; RAHMAN, 2013). 
A água da chuva é uma forma de precipitação na qual a água líquida cai na superfície da Terra. Sabe-se que água da chuva e o degelo sejam as principais fontes de toda a água potável neste mundo, e como aproximadamente $97,5 \%$ de toda a água na terra é água salgada, deixando apenas 2,5\% como água doce, que pode ser encontrada em várias formas, como geleiras e águas subterrâneas e superficiais, além de água atmosférica. Portanto, é evidente que a água doce, embora renovável, é um recurso limitado (ANNECCHINI, 2005).

Os relatórios revelaram que 768 milhões de pessoas em todo o mundo não têm acesso à água potável, o que é frequentemente denominado escassez física de água, enquanto 1,8 bilhão de pessoas deve viver em regiões com escassez absoluta de água até 2025. Isso aconteceu devido ao gerenciamento não planejado dos recursos hídricos, planejamento insuficiente e vontade política insuficiente. A escassez de água é, portanto, considerada um problema sério em todo o mundo e mitigar esse problema é um dos maiores desafios do século XXI. Uma das metas dos Objetivos de Desenvolvimento do Milênio (ODM) exige reduzir pela metade a proporção da população sem acesso sustentável a água potável segura e saneamento básico até 2015 (YEASMIN; RAHMAN, 2013).

Portanto, é evidente que existem escopos consideráveis para a coleta de água da chuva quando ela cai. O potencial da captação de água da chuva e a urgência de mitigar problemas relacionados à escassez de água também são confirmados pelo fato de muitos pesquisadores estarem trabalhando nessas questões. Conforme Vasconcelos e Ferreira (2007) deve-se fomentar a redução do consumo, buscando maior sustentabilidade.

\subsection{FINALIDADE DO REAPROVEITAMENTO DA ÁGUA}

À medida que se aproxima o fim do século $\mathrm{XX}$, a construção civil vai delineando as formas de um processo produtivo mais adequado para os próximos anos. Uma das correntes conhecidas como construção enxuta, direciona suas ações para "enxugar" a obra de todas as atividades que não geram valor, resultando em desperdício de recursos (MACHADO, 2002). 
Segundo Cohim et al (2007), deve ser reutilizada a água de residências após feitas adaptações com investimento para isso, pois embora haja gasto este terá retorno na economia feita, geralmente basta que exista a construção de um reservatório para o acúmulo da água, uma caixa de areia para decantação, um clorador e uma bomba que levaria a água do reservatório para o local de uso.

Observa-se que o Meio Ambiente é exposto pela Constituição Federal como um Direito Fundamental de todos, devendo a coletividade e o governo nacional resguardá-lo e defendê-lo de qualquer ato que provoque degradação, o que é fundamental para a organização de um meio ambiente sustentável, e no caso da água, esta é tida como um dos principais recursos naturais e do meio ambiente que deve ser cuidado e preservado (CONSTITUIÇÃO FEDERAL, 1988).

Deste modo, a partir da necessidade de se preocupar com este tema, já que os recursos eram destruídos, o ser humano passou a buscar regras para que este desmatamento e retirada de matérias primas do meio ambiente fosse sustentável, surgindo assim as normas de Direito ambiental, pautadas na busca de um ambiente equilibrado e sustentável (MININNI, 2007).

As questões ambientais passaram a ser foco de tratados, discussões, assunto político e de preocupação social, o homem percebeu que sem os recursos naturais a sua vida estaria em risco e a partir daí começaram a agir mais em prol da defesa ao meio ambiente, e com o surgimento do conceito econômico de propriedade e do desenvolvimento sustentável tais discussões foram ainda mais afloradas pois o capitalismo afetava cada vez mais o ambiente trazendo maior degradação (SIRVINKAS, 2009).

Mas este recurso que deveria se inesgotável para atender as necessidades dos seres vivos não é, e ela está cada vez mais se esgotando, e muito se deve à falta de conscientização ambiental e por simples ignorância de uma sociedade capitalista que só visa o bem estar e lucro próprios e não pensam no desenvolvimento sustentável. O homem é o ser mais fundamental para a preservação do meio ambiente, e deve fazer a sua parte com ações que preservem e não causem desastres ecológicos, 
tendo maior consciência e buscando com medidas simples reutilizar os recursos naturais e no caso da agua esse aproveitamento não deve ser diferente (SIRVINKAS, 2009).

\subsection{VANTAGENS DO REAPROVEITAMENTO DA ÁGUA}

Conforme Hespanhol (2003), existem inúmeras vantagens em se aproveitar a água já utilizada.

Machado (2002) destaca que a preocupação de não gastar água mais do que se deve é essencial e faz do reaproveitamento de água um assunto extremamente importante de ser discutido, e necessário de ser implementado, elevando a importância de preservar essa fonte de vida.

A seguir é ilustrado um sistema de captação de água da chuva muito utilizado em residências para uso não potável:

Figura 3: Sistema de captação de água da chuva

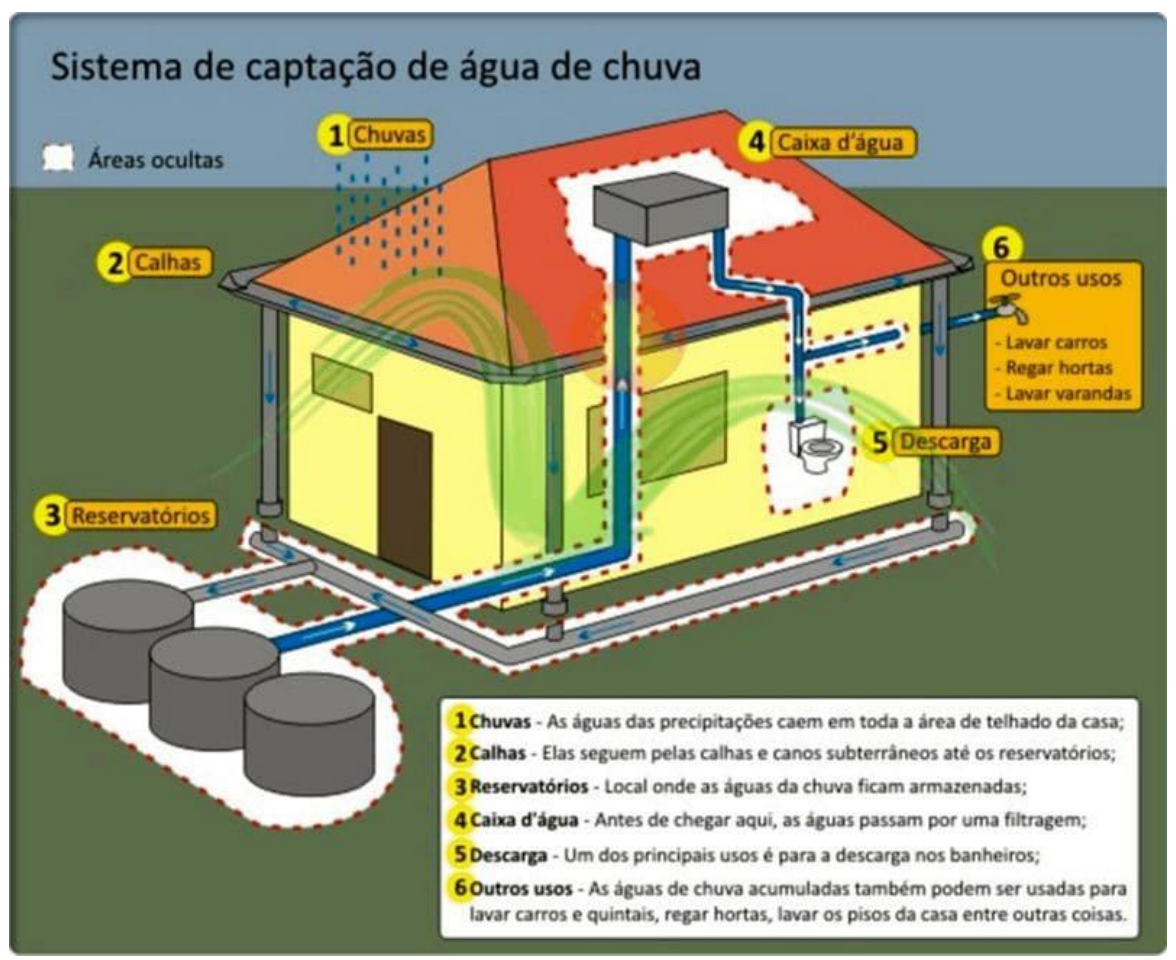

Fonte: Aragão et al., (2013).

$\mathrm{RC}: 52338$

Disponível em: https://www.nucleodoconhecimento.com.br/engenharia-civil/reutilizacao-de-agua 
Acima, nota-se que primeiramente a água da chuva precipita sobre o telhado (1), após cair é direcionada para a calha (2), que através das tubulações são levadas ao reservatório onde fica armazenada (3), daí a agua é filtrada e passa para a caixa d'agua de onde será distribuída ao uso de descarga de banheiro e ainda pode ser usada para lavar carro, lavar piso, para limpeza e para regar plantas e outras formas de uso não potável.

Buscando defender os recursos hídricos, muitos estudos trazem a possibilidade de evitar o desperdício de água, e entre eles nota-se inclusive normas e leis em prol do tema, para evitar tal desperdício, os legisladores brasileiros elaboraram a Lei no 9.433, aprovada em 1997 e que trouxe o tema da exploração das águas e do gerenciamento de recursos hídricos no Brasil, trazendo diretrizes e implementando o Planos de Recursos Hídricos bem como o sistema de cobrança pelo uso das águas (ANA, 2002).

Baseado nas tecnologias de coleta de água de chuva que sempre existiram e que progrediram dentre os séculos XIX e XX, percebeu-se que me regiões como Vitória da Conquista - Bahia, onde se têm um clima moderado e úmido, a captação e utilização de água de chuva é viável, sendo um recurso que atualmente está atrelado a conceitos e técnicas construtivas e de segurança sanitária que trazem segurança para população da qualidade da água reutilizada (COHIM, et al, 2007).

A reutilização da água é fator preponderante para evitar o desperdício e a água deve ser tratada como um bem e por isso deve ser usada com cautela, salienta-se ainda que a utilização da água de reuso na agricultura também para reduzirr o consumo de água e reduzir gastos com irrigação. A tecnologia atual permite transformar água imprópria como a do esgoto em água limpa, e esta reutilização de água pode ser uma forma de auxílio no uso da mesma na agricultura, diminuindo gastos com irrigação, e permitindo que as fontes hídricas continuem com manancial suficiente para atender a sociedade em seus lares (MORUZZI, 2008). 


\subsection{CUSTO/BENEFÍCIO DO REAPROVEITAMENTO DA ÁGUA}

Conforme Santos (et al, 2010) para que haja o reaproveitamento da água deve ser levado em conta toda técnica estará sempre condicionada à relação custo/benefício.

Desta forma, para que seja feito o reuso são investidos custos em ferramentas que tornem essa reutilização viável, e tal ação serve para racionalizar o uso dos recursos hídricos, buscando o desenvolvimento sustentável e por isso o custo para o benefício que o aproveitamento traz é bastante válido, vez que se gasta menos para implementar do que se gastaria para manter o desperdício de água caso não houvesse tal ferramenta (CUNHA et al, 2011).

Segundo Soares (2010), para que seja implementado o reaproveitamento dos recursos hídricos é necessário fazer a averiguação das tecnologias de reuso que fazem a reciclagem da água, como meio para que a reutilização da água seja uma solução eficaz que não tenha custos muito elevados em função do benefício que será trazido, sendo, portanto economicamente viável para preservação de ecossistemas e buscando trazer o desenvolvimento sustentável neste setor, ou seja, nos recursos hídricos (SOARES, 2010).

Deste modo o sistema de reutilização de recursos hídricos é viável e deve ser aplicado nos termos que se põe, vez que a captação de água para ser reutilizada e renovada para uso é válida e traz benefícios para a sociedade, tendo um custo ínfimo diante dos benefícios que traz, vez que se toda água utilizada fosse reaproveitada haveria sustentabilidade deste recurso nas gerações futuras por um tempo bem maior do que o esperado (CUNHA, et al, 2011).

Neste contexto, deve-se salientar que a água para consumo humano deve estar dentre os padrões de consumo, e para isto o reaproveitamento deve ser feito para determinado fim, ou finalidade, passando pelo processo adequado para tal. Hodiernamente, grande parte da água utilizada pode ser objeto de reuso e grande parte dela pode ser facilmente reutilizada e não dependerá de gastos exorbitantes, 
pois muitas vezes a água tem poucas impurezas e pode ser facilmente reutilizada (SOARES, 2010).

Santos et al (2010) trata que o reuso da agua é salutar e no caso da utilização de água da chuva é uma opção inteligente que pretende o racionamento dos recursos hídricos, mas que as vezes é censurada pela população tendo que perceber ainda a viabilidade mercadológica e o relatório situacional levando em conta ainda a tecnologia presente que deve ser utilizada para o uso e reaproveitamento da água.

Portanto, percebe-se que as cidades tem-se desenvolvendo de forma célere com transformação urbana rápidas e que quase sempre não foram planejadas e por isso degrada-se muito o ambiente e resultou em situação ambiental desastrosa como a degradação ambiental dos mananciais; contaminação dos rios por esgotos domésticos, industrial e pluvial e enchentes urbanas pela extensiva ocupação do espaço (SIRVINKAS, 2009).

Neste sentido, nota-se que não manter o meio ambiente ecologicamente equilibrado atuando com desperdício afeta diretamente a qualidade de vida da população e como deve-se buscar meios para resolver tais problemas dos recursos hídricos, deve-se trazer uma maior conscientização da população com tal situação que é muito preocupante, buscando por ações positivas em relação à conservação destes recursos (MORAES, 2002).

\subsection{PROCESSOS NECESSÁRIOS NO APROVEITAMENTO DA ÁGUA DA CHUVA}

De acordo com a ABNT- Associação Brasileira de Normas Técnicas, NBR 15527:2007- Aproveitamento de coberturas em áreas urbanas para fins não potáveis, a concepção do sistema de aproveitamento de água de chuva deve atender às seguintes normas: ABNT NBR 5626:1998- Instalação predial de água fria, e ABNT NBR 10844:1989- Instalações de Águas Pluviais. 


\subsubsection{CALHAS E CONDUTORES}

As calhas e condutores horizontais e verticais devem estar de acordo com a norma da ABNT NBR 10844:1989. Levando em conta o período de retorno escolhido, a vazão de projeto, a intensidade pluviométrica e a instalação de dispositivos para remoção de detritos, também de acordo com outra norma da ABNT, a NBR 12213:1992.

\subsubsection{RESERVATÓRIOS}

Os reservatórios devem atender à ABNT NBR 12217:1994-, devendo ser considerados no projeto: extravasor, dispositivo de esgotamento, cobertura, inspeção, ventilação e segurança. Ressalta-se que os reservatórios devem ser desinfetados com hipoclorito de sódio, uma vez por ano (ABNT NBR 5626:1998).

Segundo Thomaz (2005), do custo total de um sistema de aproveitamento de chuva o valor equivalente ao reservatório é de $50 \%$ a $85 \%$. Por isso o estudo deste autor destaca a importância de se usar reservatórios para armazenar água, evitando contaminação futura através de cuidados como a desinfecção destes, sendo bem cuidados.

\subsubsection{INSTALAÇÕES PREDIAIS}

O sistema de distribuição, tubulações, reservatórios e demais componentes de água de chuva devem ser independentes e claramente diferenciados do sistema de água potável, não permitindo a conexão cruzada e o uso incorreto de suas atribuições de acordo com ABNT NBR 5626:1998.

\subsubsection{BOMBEAMENTO}

Quando necessário o bombeamento, este deve atender à ABNT NBR 12214:1992Projeto de sistema de bombeamento de água para abastecimento público. Devem ser observadas as recomendações das tubulações de sucção e recalque, velocidades mínimas de sucção e seleção do conjunto motor-bomba. 


\subsubsection{MANUTENÇÃO}

A manutenção está entre os aspectos mais cruciais que abarca vários fatores como segurança do sistema e eficiência do mesmo, se esta não for feita o aproveitamento não será feito de forma adequada e por isso há normas técnicas para efetivar este passo.

\subsubsection{DESCARTE DA ÁGUA DE LAVAGEM DO TELHADO}

Segundo o Manual de Saneamento divulgado pela Fundação Nacional de Saúde (FUNASA, 2006) o descarte da água coletada na fase inicial da precipitação deve ser feito a fim de evitar que as contaminações provenientes da área de captação sejam direcionadas aos reservatórios ou cisternas.

De acordo com Costa (2009), o procedimento mais seguro e eficiente de proteção sanitária antes do armazenamento é feito utilizando-se dispositivos automáticos de desvio e descarte das primeiras águas de cada chuva, Será analisando nos resultados e discussões neste estudo alguns sistemas de aproveitamento de água da chuva pelo telhado.

\subsection{REAPROVEITAMENTO DA ÁGUA DA CHUVA E SUA IMPORTÂNCIA NA CONSTRUÇÃO CIVIL}

Nota-se que a construção civil é uma das atividades humanas que mais causam danos ao meio ambiente no mundo. Sendo assim, questiona-se o desperdício de recursos naturais na construção civil se atualmente com grande dimensão pode ser reduzido. Diante disso é válido destacar que estudos analisados demonstraram, a exemplo de Lima (2012), Aragão et al (2013), May (2004), que espera-se com a implementação de reutilização da água uma melhora na sustentabilidade, mostrando que é simples tal implementação e como já visto anteriormente traz muitos benefícios, que é a preocupação atual para manter recursos para gerações futuras. Sendo assim, a principal vantagem deste projeto é de ser um modelo de aproveitamento de recursos hídricos que poderiam ser perdidos na natureza e que serão utilizados. 
Entre os objetivos deste trabalho buscou-se apresentar as principais nuances a respeito deste processo, destacando os tipos mais relatados na literatura acerca do aproveitamento de água, e ao resumir os mais citados, conseguiu-se destacar nove métodos, tendo todos estes excelente aplicação prática e ótimo custo benefício, conforme os estudos averiguados e propostos com esta temática que leva em consideração o uso de água e evitar seu desperdício, com métodos seguros, e diante disso, a tabela 2 infra mencionada destaca-se os principais métodos e sua aplicação técnica e viabilidade econômica.

Tabela 2: Métodos de aproveitamento/reuso de água e aplicação

\begin{tabular}{|c|c|}
\hline Método & Análise técnica \\
\hline Rippl & $\begin{array}{l}\text { É o método mais usado, averígua-se a necessidade da } \\
\text { demanda de água e geralmente super dimensiona o } \\
\text { reservatório. Nesse método é possível usar as séries } \\
\text { históricas mensais ou diárias }\end{array}$ \\
\hline Simulação & $\begin{array}{l}\text { Modo de calcular a cisterna para água da chuva (também } \\
\text { estabelece o volume para reservatório) }\end{array}$ \\
\hline Azevedo Neto & $\begin{array}{l}\text { O volume de chuva é obtido pela equação: } \mathrm{V}=0,042 \times \mathrm{P} \times \mathrm{A} \\
\mathrm{x} \mathrm{T} \text {, Onde: } \mathrm{V} \text { : valor numérico do volume de água aproveitável } \\
\text { e o volume de água do reservatório, } \mathrm{P} \text { : valor numérico da } \\
\text { precipitação média anual, expresso em mm; A: valor da área } \\
\text { de coleta em projeção, expresso em } \mathrm{m}^{2} ; \mathrm{T} \text { : valor numérico do } \\
\text { número de meses de pouca chuva ou seca. }\end{array}$ \\
\hline Prático alemão & $\begin{array}{l}\text { Esse método empírico adota como valor de volume do } \\
\text { reservatório o valor mínimo entre } 6 \% \text { do volume anual do } \\
\text { consumo e } 6 \% \text { do volume anual da precipitação aproveitável, } \\
\text { de acordo com a equação: } V=\min (\mathrm{V} ; \mathrm{D}) \times 0,06\end{array}$ \\
\hline Prático Inglês & $\begin{array}{l}\text { O volume de chuva é obtido pela equação: } \mathrm{V}=0,05 \times \mathrm{P} \times \mathrm{A} \text {. } \\
\text { Onde: V: volume de água aproveitável e o volume do } \\
\text { reservatório adotado, expresso em litros; } \mathrm{P} \text { : valor numérico da }\end{array}$ \\
\hline
\end{tabular}




\begin{tabular}{|c|c|}
\hline & $\begin{array}{l}\text { precipitação média anual, expresso em mm; A: valor numérico } \\
\text { da área de coleta em projeção, expresso em m². }\end{array}$ \\
\hline Prático Australiano & $\begin{array}{l}\text { O volume de chuva é obtido pela equação: } \mathrm{Q}=\mathrm{A} \times \mathrm{C} \times(\mathrm{P}-\mathrm{I}) \text {. } \\
\text { Onde: } \mathrm{Q} \text { : volume mensal produzido pela chuva; } \mathrm{A} \text { : área de } \\
\text { coleta; C: coeficiente de escoamento superficial, em geral } \\
0,80 \text {; P: precipitação média mensal; I: interceptação da água } \\
\text { que molha as superfícies e perdas por evaporação, } \\
\text { geralmente } 2 \mathrm{~mm} \text {. }\end{array}$ \\
\hline $\begin{array}{l}\text { Máximo } \\
\text { aproveitamento }\end{array}$ & Não depende do fornecimento de água de fora perene. \\
\hline Dimensionamento & $\begin{array}{l}\text { Viabilidade em qualquer estação, adequando o } \\
\text { dimensionamento do reservatório. }\end{array}$ \\
\hline DESVIUFPE & Armazena água que iria ser descartada \\
\hline
\end{tabular}

Fonte: Própria Pesquisa (2020).

A NBR 15527 trata do aproveitamento de água de chuva para fins não potáveis em áreas urbanas (ABNT, 2007), Mas a NBR não traz todos os métodos existentes, e estudo de Moruzzi (2008) destaca outro que é o método do máximo aproveitamento que visa reduzir a demanda de água potável, não dependendo do fornecimento de água de chuva, tal método é interessante para contribuir com a disseminação do uso de água de chuva em fins não potáveis. Pois, de acordo com a ANA (2002) deve buscar projetos e fundamentos para a reutilização dos recursos hídricos, e no caso do reaproveitamento da água da chuva é ainda mais fácil, vez que esta e coletada, passa por filtragem e vai para um reservatório até ser bombeada para uma caixa que a reserva e a partir desta será distribuída para que haja o reuso.

Cohim et al. (2007) traz outro método para dimensionamento de reservatório, que leva em consideração a época do ano, não estando potente apenas em época de chuva, já que no ano, há divergência no índice pluviométrico e demanda nos volumes de reservatórios, tendo, portanto esse sistema uma boa viabilidade e que traz melhoras também no aspecto econômico, pois gera diminuição do consumo de água potável. Percebe-se ainda que nos meses entre novembro e janeiro a quantidade de chuvas e 
frequência das mesmas é maior, seguido por março, mas estas são equilibradas durante todo ano, não tendo nenhum período de seca completa, mostrando a viabilidade para o aproveitamento de água captada na chuva.

Oliveira (2004) em estudo feito também com uso de sistema de reaproveitamento de água destaca que o profissional deve atentar para muitos aspectos referentes a implementação de sistemas de reaproveitamento de água e para isso deve conhecer dados pluviométricos de duração, intensidade e frequência, para que o engenheiro determine dados de vazão máxima, sendo recorrente seu uso em projetos de obras hidráulicas, sendo salutar destacar que nem sempre os dados acerca da vazão são facilmente encontrados, ou sequer são existentes, ou são insuficientes, por isso a importância de saber fazer o estudo de chuvas intensas da região é crucial e determinante para o sucesso do projeto.

Aragão et al (2013) destaca que o profissional da construção civil deve-se atentar para atender tal exigência com uso da equação do tipo intensidade duração-frequência (equações de chuvas intensas) pautadas nos dados pluviógraficos específicos da região analisada. Nota-se que muitas questões devem ser consideradas para que se faça o aproveitamento de recursos pluviais, como por exemplo, os índices pluviométricos, pois de nada adiantaria fazer um sistema de captação de água da chuva em locais de extrema seca e no qual as chuvas são escassas.

Nota-se que os estudos analisados demonstraram vantagens tanto aos engenheiros como aos clientes, pois quando estes forem informados dos reais benefícios irão se abrir com maior facilidade a ideia de captação da água da chuva, auxiliando para que os recursos naturais do ecossistema não se esgotem como vem ocorrendo e para que estes tenham maiores benefícios financeiros com a implementação do projeto.

Lima (2012) destaca ainda que para captar água da chuva o material usado é simples e engloba telhado, laje ou piso (área de captação), calhas, condutores verticais e horizontais (sistemas de condução de água), reservatório de limpeza, filtros e desinfecção (unidade de tratamento) e reservatório de acumulação, tendo estes elementos pode-se montar um sistema de captação e aproveitamento de água de 
chuva, as alterações neste vai depender de como o sistema deve ser montado e qual objetivo e poderá necessitar que se acrescente mais algum material como por exemplo reservatório superior ou sistema de bombeamento.

Estudo Feito por May (2004) sobre a viabilidade de aproveitamento de água da chuva destaca que vai ter que ser feita uma análise de cada local de forma específica para então montar o sistema adequado. Esta autora descreve que em um sistema de coleta e utilização de águas da chuva os telhados são os mais usados como áreas impermeáveis para a coleta, salientando que após a água ser captada ela passa por um filtro e depois é direcionada para os reservatórios de acumulação, que podem ser enterrados, elevados ou apoiados.

Outro exemplo de aplicação de dispositivo de desvio das primeiras águas de chuva, no qual o dispositivo automático de descarte de primeira água da chuva, denominado DESVIUFPE é simples e de baixo custo, confeccionado apenas com tubos de PVC (Policloreto de Vinila), conforme mostrado na Figura 4; consiste basicamente em armazenar a água de descarte ao longo do sistema, permitindo um redirecionamento e armazenamento das demais águas para o reservatório.

Figura 4: Esquema da instalação experimental do Campus do Agreste da UFPE

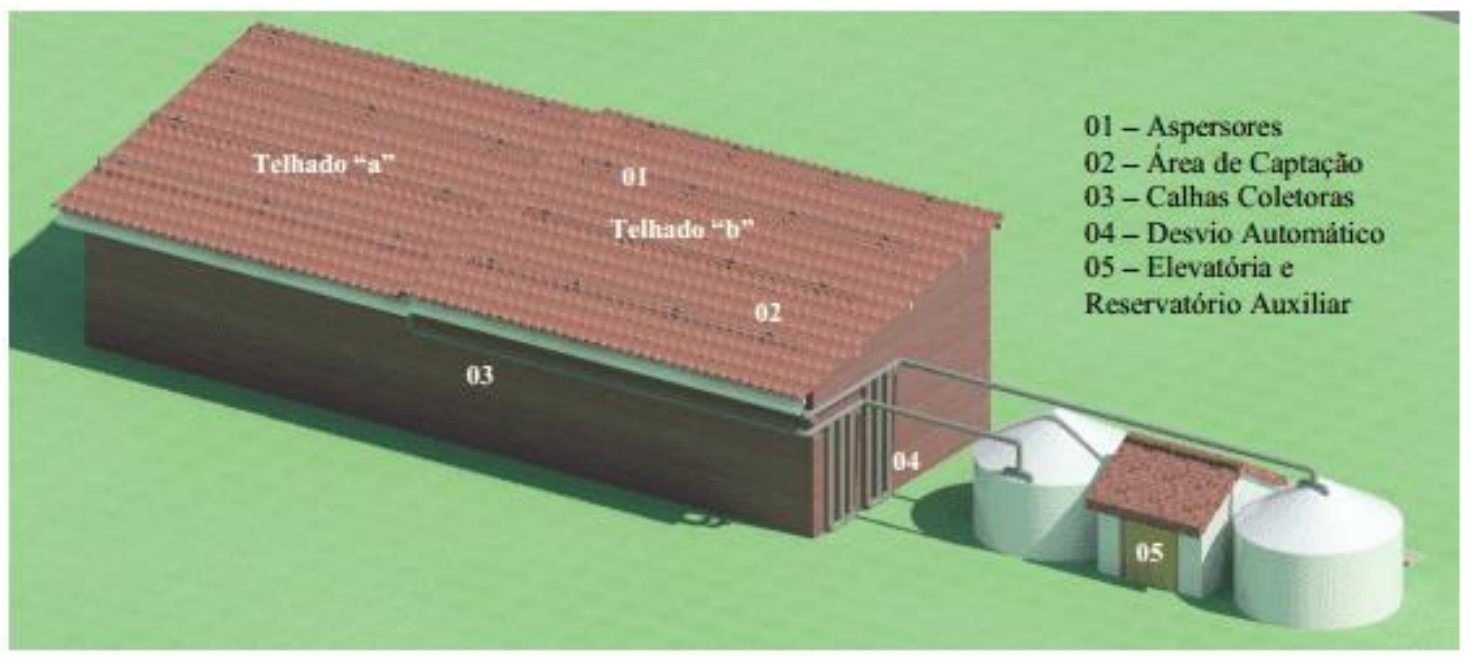

Fonte: LIMA (2012). 
A avaliação do sistema acima descrito foi feita dentro de um período de 25 meses e foram instalados na zona rural de Caruaru e no laboratório experimental, localizado no campus da Universidade Federal do Pernambuco; a conclusão dos resultados indicou melhoria significativa das águas armazenadas, o dispositivo foi capaz de reduzir de $67 \%$ a $100 \%$ o teor das impurezas. Segundo Lima (2012), o dispositivo reduziu os coliformes totais e a turbidez, enquadrando a qualidade da água aos níveis aceitáveis de potabilidade, passando a ser uma água própria para o consumo não potável (Portaria n²914/2011), exceto o bacteriológico.

Os estudos confirmaram também a viabilidade técnica do sistema, configurando como barreira sanitária à contaminação da água e indicou que o desvio do primeiro milímetro de chuva é extremamente importante para garantir o encaminhamento de água de boa qualidade às cisternas ou reservatórios.

Visando facilitar a análise e resumir, de modo compreensivo, os resultados obtidos nesta pesquisa, nota-se que quanto a viabilidade econômica da captação de água da chuva, esta é bastante válida, conforme dita Dias (2008) o desperdício de água nas residências é bastante oneroso e o chuveiro, a descarga sanitária são fatores de alto consumo de recursos hídricos, claro que a viabilidade econômica depende do padrão de consumo de cada residência, mas no modelo implementado é válida e eficaz como forma de economizar água.

Notando que o custo é um custo razoável, levando em consideração os benefícios que trará e a economia de água que haverá na residência com o passar do tempo a partir da implementação desta estrutura, o gasto é inicial, mas com o passar do tempo a economia no uso de água além de retornar o valor gasto ainda denota consciência ambiental do proprietário do imóvel (COHIM, et al, 2007).

Nota-se inclusive que para implementação destes sistemas podem ser feito em etapas e ser incentivado através de linhas de financiamento como incentivos de programas sustentáveis em habitação. Sobre essas linhas de financiamento, existem leis no ordenamento jurídico brasileiro que tutelam que tais linhas de financiamento para o uso sustentável da moradia seja incentivado, deste modo Dias (2008) dita que bancos 
públicos e privados tem linhas e programas voltados para essa medida, em respeito as normas federais incorporadas que devem ser atendidas.

Sendo assim a principal vantagem destes projetos é de ser um modelo de aproveitamento de recursos hídricos que poderiam ser perdidos na natureza e que serão utilizados. O fator que dificulta este tipo de implementação é advindo da falta de consciência do homem na filosofia de vida nas cidades, que não consegue enxergar que a água faz parte de um ciclo hidrológico e existe um custo altíssimo para transportá-la até as torneiras. Deste modo, é perceptível que a falta de conscientização humana no desenvolvimento sustentável e aproveitamento de recursos é o que mais impossibilita a renovação de energias e recursos e ainda continua sendo o fator principal a degradação ambiental (DIAS, 2008).

\section{CONSIDERAÇÕES FINAIS}

Conforme averiguado neste estudo, o aproveitamento de água de chuva para uso não potável, na construção civil é um tipo de alternativa viável que pode ser implementada em casas como forma de trazer economia no gasto de água e ainda tutelar este recurso natural, evitando seu desperdício.

Como resultados da pesquisa analisou-se estudos que tratam do reaproveitamento da água da chuva e elencando os benefícios para a Engenharia civil, destacando o uso de tecnologias em favor do aproveitamento da água, podendo citar o sistema de aproveitamento da água da chuva denominado telhado verde, os sistemas de implementação de reutilização da água em prol da sustentabilidade, que aproveitam recursos hídricos que poderiam ser perdidos na natureza, citando ainda os métodos de dimensionamento de reservatório de água de chuva propostos na NBR 15527:2007 que foi considerado mais eficiente que o Decreto Municipal 293/2006, de Curitiba, PR, descrevendo ainda o método do máximo aproveitamento que visa reduzir a demanda de água potável e ainda o método para dimensionamento de reservatório. Outro exemplo de aplicação de dispositivo de desvio das primeiras águas de chuva, com ferramenta automática de descarte de primeira água da chuva, denominado DESVIUFPE também foi citado. 
Salienta- se que todos estes sistemas e estudos serviram para atentar sobre a importância de realizar o aproveitamento de água da chuva, analisando a viabilidade técnica do sistema em cada caso e evitando o desperdício de água, por isso usar as tecnologias cabíveis para captar estes recursos da natureza é mais que viável em prol do desenvolvimento sustentável do planeta.

Viu-se que para implementar estas intervenções são necessários poucos materiais e o uso de tecnologia simples, tendo um custo razoável, trazendo benefícios a longo prazo e que além de ser viável economicamente este ainda pode ser feito pelas linhas de financiamento que existem como incentivos de programas sustentáveis.

Percebeu-se com este estudo que atitudes como esta são de extrema importância, e devem servir de exemplo, já que em cidades em pleno crescimento a degradação ambiental é ainda maior e a transformação urbana rápida afeta diretamente no ecossistema e destrói muitos recursos naturais através da degradação e desperdício.

Diante disso destaca-se ainda a expectativa de retorno econômico destes métodos, que visa evitar o gasto com uso de água, evitando o desperdício, e por isso a sua aplicação gera excelente custo benefício, pois não são sistemas caros e que geram o retorno no momento que a água passa a ser reutilizada, evitando gastos maiores para a função antes usada.

Assim, tal estudo é marcado por demonstrar essa forma de reaproveitamento como meio de sustentabilidade, sendo viável economicamente e de fácil implementação, devendo com isso fomentar uma nova conscientização humana em prol do desenvolvimento sustentável e de medidas que degradem menos o meio ambiente, fazendo assim com que se crie uma sociedade que enxergue as necessidades das gerações futuras como uma preocupação presente e que no caso dos recurso hídricos a sua reutilização, uso, reuso e captação são meios de amenizar esta realidade tão preocupante que assola a natureza.

Diante disso, este estudo discutiu que o reaproveitamento com a captação de água da chuva para fins de uso da construção civil utilizado principalmente em residências 
é um método que serve de base para formação da consciência individual de cada cidadão no seu dia a dia na luta por um ambiente sustentável que deve começar dentro das casas de cada um, pois ações pequenas em conjunto fazem grande diferença, inclusive para o futuro da humanidade.

\section{REFERENCIAS}

ABNT. Associação Brasileira de Normas Técnicas. NBR 5.626 - Instalação predial de água fria, 1998.

ABNT. Associação Brasileira De Normas Técnicas. NBR 10844 - Instalações de Águas Pluviais, 1989.

ABNT. Associação Brasileira de Normas Técnicas. NBR 12213 - Projeto de captação de água de superfície para abastecimento, 1992.

ABNT. Associação Brasileira de Normas Técnicas. NBR 12214 - Projeto de sistema de bombeamento de água para abastecimento público, 1992.

ABNT. Associação Brasileira de Normas Técnicas. NBR 12217- Projeto de reservatório de distribuição de água para abastecimento público, 1994.

ABNT. Associação Brasileira de Normas Técnicas. NBR 15.527 - Aproveitamento de coberturas em áreas urbanas para fins não potáveis, 2007.

ALMEIDA, CP; ALVES, JAS; BUENO, LG; ABREU, MR. Aproveitamento de água de chuva para fins não potáveis em áreas urbanas. Universidade Anhembi Morumbi. Trabalho de Conclusão de Curso. São Paulo-SP, 2010.

ANA; FIESP; SindusCon-SP. Conservação e Reuso da Água em Edificações. São Paulo: Prol Editora Gráfica. 2005.

ANA - Agência Nacional de Águas. A Evolução da Gestão dos Recursos Hídricos no Brasil / The Evolution of Water Resources Management in Brazil. Brasília; ANA, 2002. 
ANNECCHINI, KPV. Aproveitamento da Água da Chuva Para Fins Não Potáveis na Cidade de Vitória (ES). Universidade Federal do Espírito Santo, Centro Tecnológico, Programa de pós-graduação em engenharia ambiental. Trabalho de Conclusão de Curso. Vitória - ES, 2005.

ANTUNES, Paulo de Bessa. Direito Ambiental. 7 ed. Rio de Janeiro: Lúmen Júris, 2004.

ARAGÃO, R. de. SANTANA, G. R. de; COSTA, C. E. F. F. da.; CRUZ, M. A. S.;FIGUEIREDO, E. E. de. SRINIVASAN V. S. Chuvas intensas para o estado de Sergipe com base em dados desagregados de chuva diária. Revista Brasileira de Engenharia Agrícola e Ambiental. Campina Grande, v.17, n.3, p.243-252, 2013.

BRASIL. IBGE. Dados a respeito do consumo de água populacional. (Instituto Brasileiro de Geografia Estatística) - www.ibge.gov.com acesso em 10 mar 2020.

COHIM. Eduardo; GARCIA. Ana; KIPERSTOK. Asher. Captação e Aproveitamento de Água de Chuva: dimensionamento de reservatórios. IX Simpósio de Recursos Hídricos do Nordeste. 2007.

COSTA, M.R. Qualidade e sustentabilidade hídrica: avaliação de estratégias e políticas de convivência com o semiárido. Tese de Doutorado, Universidade Federal de Pernambuco, Recife.2009.

CUNHA. Ananda Helena Nunes; OLIVEIRA. Thiago Henrique de; FERREIRA. Rafael Batista. MILHARDES. André Luiz Mendes; COSTA E SILVA. Sandra Máscimo da. 0 reúso de água no Brasil: a importância da reutilização de água no país. Enciclopédia Biosfera, Centro Científico Conhecer - Goiânia, v.7, n.13; 2011.

DIAS. Thiago. Sustentabilidade e economia com o reúso de água. Edição 35, 2008. Disponível em:< http://www.meiofiltrante.com.br/materias_ver.asp?action $=$ detalhe\&id=430>Acesso em 09 mar 2020. 
FUNASA - Fundação Nacional de Saúde. Manual de Saneamento. Brasília-DF, 407 p., 2006.

FURRIELA. Rachel Biderman. Aspectos jurídicos e práticos do estudo de impacto ambiental e relatório de impacto sobre o meio ambiente ( EIA- RIMA). Artigo. scielo. 2002.

HESPANHOL, I. Potencial de reuso de água no Brasil: agricultura, indústria, municípios, recarga de aquíferos. Bahia Análise \& Dados Salvador, v. 13, n. Especial, p. 411-437, 2003.

JUNIOR, Jose de Sena Pereira. Recursos Hídricos - Conceituação, Disponibilidades e Usos. Brasília: Consultoria Legislativa da Câmara dos Deputados, 2004.25p.

LIMA, Júlio Cesar Azevedo Luz de. Avaliação do desempenho de dispositivo de desvio das primeiras águas de chuva utilizado em cisternas no semiárido pernambucano. Dissertação (Mestrado). Recife, 2012.

MACHADO, Paulo Affonso Leme. Recursos Hídricos - Direito Brasileiro e Internacional. Malheiros Editores: São Paulo, 2002.

MAY, Simone. Estudo da viabilidade do aproveitamento de água de chuva para consumo não potável em edificações, São Paulo. Dissertação (Mestrado) - Escola Politécnica da Universidade de São Paulo. Departamento de Engenharia de Construção Civil. 2004, 159p.

MININNI, Nana Medina. Breve histórico da educação ambiental. Disponível em : $<$ http://www.pm.al.gov.br /bpa/publicacoes/ed_ambiental.pdf> Brasília, IBAMA. Acesso em 02 mar 2020.

MORAES, Luís Carlos Silva de. Curso de Direito Ambiental. São Paulo: Atlas, 2002. 
MORUZZI. Rodrigo Braga. Reúso de água no contexto da gestão de recursos hídricos: impacto, tecnologias e desafios, OLAM - Ciência \& Tecnologia, Rio Claro- SP, Ano VIII, Vol. 8, 2008.

OLIVEIRA, Yuri Vieira de. Uso do balanço hídrico seriado para o dimensionamento de estrutura de armazenamento de água de chuvas: estudos de casos. Dissertação (Mestrado em Engenharia Ambiental) - Centro Tecnológico da Universidade Federal de Santa Catarina, Florianópolis, 2004. Disponível em: <http://www.tede.ufsc.br/teses/PGEA0190.pdf>. Acesso em: 11 mar 2020.

PNCDA, Programa Nacional de Combate ao desperdício de Água. Apresentação do programa A1. Ministério do Planejamento e Orçamento. Secretaria de Política Urbana, Brasília, 2002,p. 48.

SANTOS, I. dos,. et al. Hidrometria aplicada. Curitiba: Instituto de Tecnologia para o Desenvolvimento, 2001.

SANTOS. Silvânia Lucas; BARROS. Antônio Ricardo Mendes. CHAVES. Jarbas Rodrigues. SANTOS. Elivânia Vasconcelos Moraes dos. Avaliação de custo/benefício do projeto de reúso de águas do IFCE- Limoeiro do Norte, 2010.

SIRVINKAS, Luís Paulo. Tutela Penal do Meio Ambiente e breves considerações atinente a lei no 9.605/98 . 2 ed. São Paulo: Saraiva, 2009

SOARES. Raquel Baraldi Ramos. Introdução a avaliação dos impactos ambientais, 2010. texto da graduação do curso de Ecologia/Unesp - Rio Claro.

TIBAYUKA, A, K (UN-HABITAT) Rain water Harvesting and Utilisation, United Nations Human Settlements Programme 50-60 Kenya. 2008,

THOMAZ, PLINIO. Poluição Difusa. São Paulo, Navegar, 2005, ISBN: 857678-70-1.

UNESCO. Report - 4 - WWAP - world water assessme programme. PARIS: UNESCO, 2012. 
VASCONCELOS, L.F; FERREIRA, O.M. Captação de Água de Chuva para uso Domiciliar: Estudo de Caso, Universidade Católica de Goiás 2007.

YEASMIN, S; RAHMAN, K. F. Potential rainwater harvesting in Dhaka city: an empirical study. ASA University Review, v. 7, n. 1, p. 143-150, 2013.

Enviado: Maio, 2020.

Aprovado: Junho, 2020. 